\title{
Primary Vaginal Non-Hodgkin Lymphoma
}

\author{
Pamela Contreras-Chavez ${ }^{1}$, Rolig Aliaga ${ }^{2}$, Mohammed Samee ${ }^{1}$, Andrea Anampa-Guzmán ${ }^{3}$ \\ 1. Internal Medicine, Advocate Illinois Masonic Medical Center, Chicago, USA 2. Oncology, Hospital Nacional \\ Arzobispo Loayza, Lima, PER 3. Internal Medicine, Universidad Nacional Mayor De San Marcos, Lima, PER
}

Corresponding author: Andrea Anampa-Guzmán, andreaangu11@hotmail.com

\begin{abstract}
Non-Hodgkin lymphoma (NHL) is a type of blood cancer and $25 \%$ of NHL patients present with a primary extranodal tumor. Primary NHL of the vagina is extremely rare with only a few cases reported. We present the case of a 79-year-old, grand multipara, Peruvian woman with an eleven-month history of symptoms of pelvic and vaginal pain and vaginal bleeding. Vaginal examination revealed an exophytic tumor that involved the labia, right vaginal wall, cervix, parametrium, and pelvic bone. A computed tomography (CT) image showed a $10 \times 10 \times 9-\mathrm{cm}$ solid tumor in the pelvic cavity with irregular edges in the pelvic floor, parametrium, and the perineal soft tissues. Bilateral pelvic and inguinal adenomegalies were found. No signs of metastases were found. Marrow and bone biopsy studies were negative. The diagnosis was NHL type diffuse large B-cell lymphoma (DLBCL) of vagina stage one. The patient was treated with six courses of CHOP-R (cyclophosphamide, doxorubicin, vincristine, prednisone, and rituximab). She showed a complete response and remained in remission in follow-up control visits. NHL of the female genital tract is rare. CHOP-R is the first line of treatment for this type of cancer. However, less is known about the follow-up protocol and relapse management. Vaginal lymphoma has an extremely low prevalence, and collaborative studies are required to study the same.
\end{abstract}

Categories: Internal Medicine, Obstetrics/Gynecology, Oncology

Keywords: hematologic malignancy, vagina

\section{Introduction}

Non-Hodgkin lymphoma (NHL) is a group of lymphoid malignancies, which typically develop in the lymph nodes but may occur in almost any tissue. Twenty-five percent of NHL patients present with a primary extra-nodal tumor [1]. Ninety percent of the NHL cases are of B-cell origin and 10\% derived from T cells or natural killer (NK) cells. NHLs have a different range of histological appearances and clinical features at presentation. Diffuse large B-cell lymphoma (DLBCL) is the most common subtype of NHL, representing about a third of cases [2].

Received 10/03/2018

Review began 10/09/2018 Review ended 12/09/2018 Published 12/11/2018

○ Copyright 2018 Contreras-Chavez et al. This is an open access article distributed under the terms of the Creative Commons Attribution License CC-BY 3.0., which permits unrestricted use, distribution, and reproduction in any medium, provided the original author and source are credited.
Hematologic malignancies rarely present as a primary gynecologic problem. They usually occur as a result of the systemic dissemination of the tumor cells rather than the primary tumor. Extranodal NHL often involves the gastrointestinal tract and the bone marrow. Less than $0.5 \%$ of all extranodal NHLs involves the female genital tract [3]. Primary NHLs of the vagina is extremely rare with only a few cases reported [4-5].

\section{Case Presentation}

A 79-year-old Peruvian woman presented with 10 months of vaginal bleeding and a vaginal tumor that was exophytic involving the cervix and extending to the right vaginal wall. There was a right tumoral mass that involved the sub-epithelium of the labia to the pelvic bone. The right parametrium was invaded until the pelvic bone. Computerized tomography (CT) scans showed a large solid tumor mass $(10 \times 10 \times 9 \mathrm{~cm})$ in the pelvic cavity with irregular edges that infiltrated the pelvic floor, parametrium, and the perineal soft tissues (Figure 1). 


\section{Cureus}

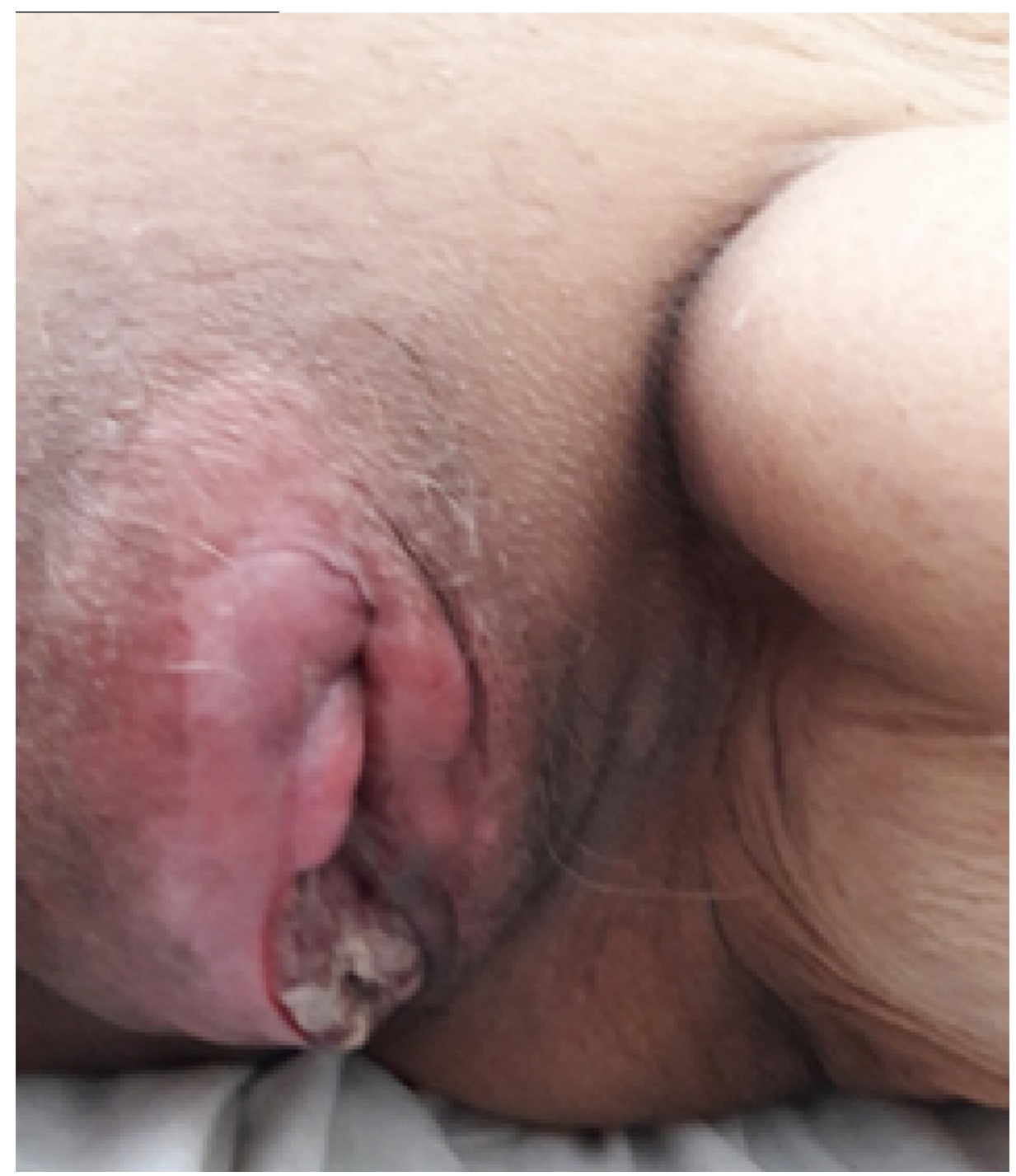

\section{FIGURE 1: Pre-treatment}

Hematoxylin-eosin showed a proliferation of the hyperchromatic cells with nuclear pleomorphism associated with an apparently red cell neoplasm. Immunohistochemistry was negative for Pankeratin, Melan-A, S100, and CD3. CD20, BCL2, BCL6, CD10, MU-1, and C-MYC were positive. Ki-67 was positive and over-expressed in $70 \%$ of the cells. Chest CT showed an interstitial reticular pattern and no signs of nodules and lung masses. Bone marrow and bone biopsy were negative. The final diagnosis was vaginal NHL of large $\mathrm{B}$ cells, with the primary central germinal phenomenon, stage IE with a bulky mass.

The initial treatment was CHOP-R (cyclophosphamide, doxorubicin, vincristine, and prednisone, plus rituximab). The patient completed six courses of CHOP-R chemotherapy. The last clinical evaluation showed a complete clinical response (Figure 2). The patient was under control. 


\section{Cureus}

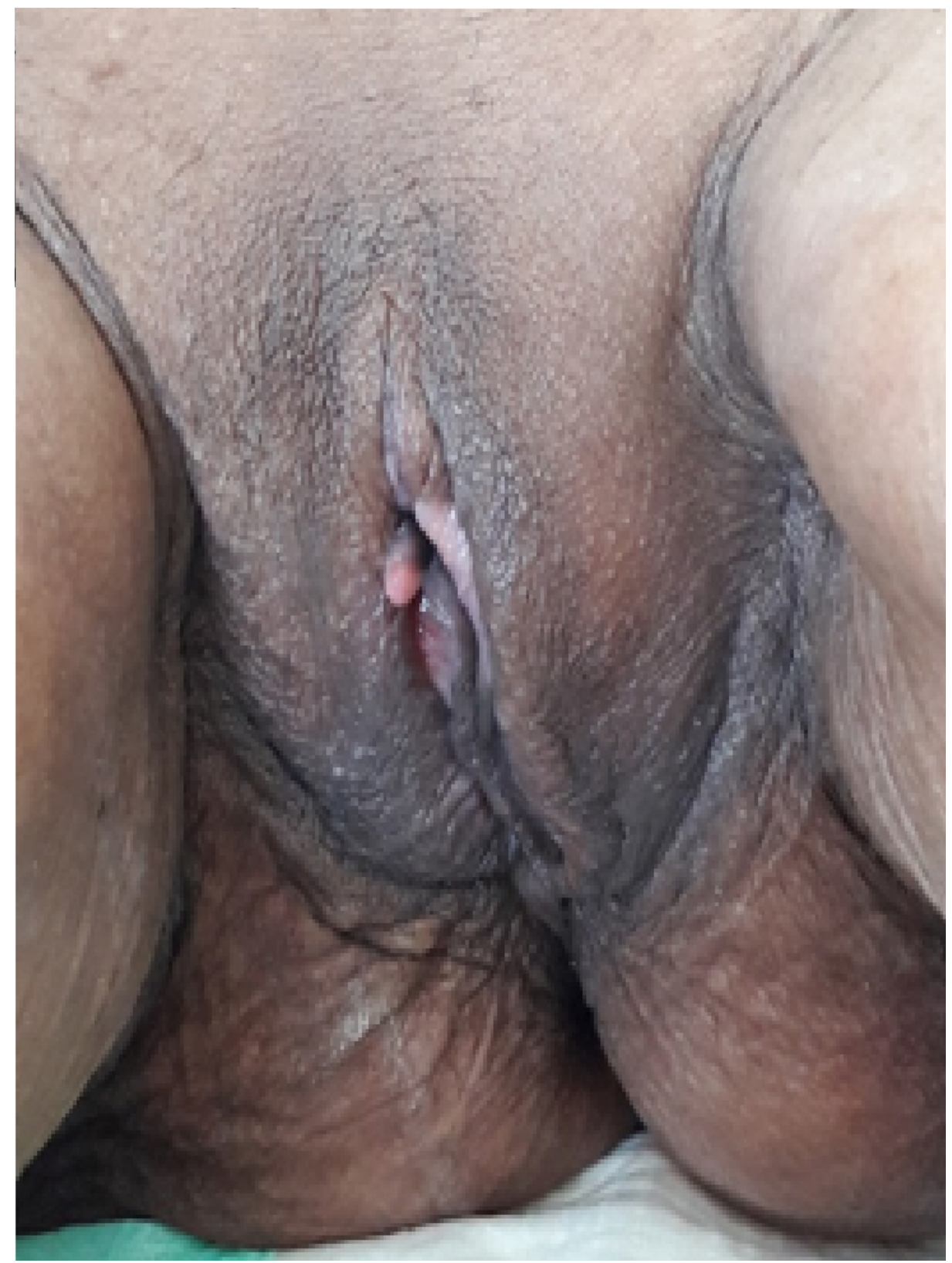

FIGURE 2: Post-treatment

\section{Discussion}

NHLs are a large group of lymphoid neoplasms, with different morphologic, immunophenotypic, and genetic characteristics. NHL of the female genital tract is rare [6]. The primary NHLs of the female genital tract involve the cervix in the majority of cases. The second most common sites are the ovaries and the uterine corpus [7]. The largest series of malignant lymphomas involve the female genital organs; primary vaginal NHLs account for less than $<0.1 \%$ [8].

Primary vaginal lymphomas have been reported in women of age 26 to 66 years [9]. This lymphoma presents most often with a vaginal mass. The tumor is usually infiltrative with a thick vaginal wall [7]. Like in our case, the most common type of primary vaginal NHL is DLBCL [6]. Patients may also complain of abnormal vaginal bleeding, mass at the introitus, dyspareunia, vaginal discharge, and irritative urinary symptoms [910]. The Lugano classification is the current staging system for patients with NHL [11]. Our case was stage IE.

Due to its rarity, there is no established treatment for primary NHL of the vagina. The first line of treatment for NHL is chemotherapy since NHLs are extremely responsive to it [12]. The treatment for limited-stage DLBCL is CHOP-R, including cyclophosphamide, doxorubicin, vincristine, prednisone, and rituximab, a monoclonal antibody directed against the CD20 antigen. Radiation therapy can either be added or not at all [13]. The primary pelvic lymphomas have a five-year survival rate of $80 \%$ to $90 \%$ if the diagnosis was made 
early and therapy was adequate [14]. Our case had a good outcome similar to these statistics.

\section{Conclusions}

Vaginal lymphoma has an extremely low prevalence. CHOP-R is the first line of treatment for this type of cancer. However, little is known about the follow-up protocol and relapse management. More collaborative studies are required to study vaginal lymphoma.

\section{Additional Information \\ Disclosures}

Human subjects: Consent was obtained by all participants in this study. Conflicts of interest: In compliance with the ICMJE uniform disclosure form, all authors declare the following: Payment/services info: All authors have declared that no financial support was received from any organization for the submitted work. Financial relationships: All authors have declared that they have no financial relationships at present or within the previous three years with any organizations that might have an interest in the submitted work. Other relationships: All authors have declared that there are no other relationships or activities that could appear to have influenced the submitted work.

\section{References}

1. Shankland KR, Armitage JO, Hancock BW: Non-Hodgkin lymphoma. Lancet Lond Engl. 2012, 1:848-57. 10.1016/S0140-6736(12)60605-9

2. Pfreundschuh M, Trümper L, Osterborg A, et al.: CHOP-like chemotherapy plus rituximab versus CHOP-like chemotherapy alone in young patients with good-prognosis diffuse large-B-cell lymphoma: a randomised controlled trial by the MabThera International Trial (MInT) Group. Lancet Oncol. 2006, 7:379-91. 10.1016/S1470-2045(06)70664-7

3. Ragupathy K, Bappa L: Primary vaginal non-Hodgkin lymphoma: gynecologic diagnosis of a hematologic malignancy. J Low Genit Tract Dis. 2013, 17:326-9.

4. Trenhaile TR, Killackey MA: Primary pelvic non-Hodgkin's lymphoma . Obstet Gynecol. 2001, 97:717-20.

5. Ferlay J, Soerjomataram I, Dikshit R, et al.: Cancer incidence and mortality worldwide: sources, methods and major patterns in GLOBOCAN 2012. Int J Cancer. 2015, 1:359-386. 10.1002/ijc.29210

6. Vang R, Medeiros LJ, Ha CS, Deavers M: Non-Hodgkin's lymphomas involving the uterus: a clinicopathologic analysis of 26 cases. Mod Pathol. 2000, 13:19-28. 10.1038/modpathol.3880005

7. Olde Scholtenhuis MAG, Bakker RW, Blaauwgeers JLG: Non-Hodgkin lymphoma of the female genital tract. A five case series. Eur J Obstet Gynecol Reprod Biol. 2002, 5:49-51.

8. Kosari F, Daneshbod Y, Parwaresch R, Krams M, Wacker H-H: Lymphomas of the female genital tract: a study of 186 cases and review of the literature. Am J Surg Pathol. 2005, 29:1512-20. 10.1097/01.pas.0000178089.77018.a9

9. Lagoo AS, Robboy SJ: Lymphoma of the female genital tract: current status . Int J Gynecol Pathol. 2006, 25:1-21. 10.1097/01.pgp.0000183049.30212.f9

10. Cohn DE, Resnick KE, Eaton LA, deHart J, Zanagnolo V: Non-Hodgkin’s lymphoma mimicking gynecological malignancies of the vagina and cervix: a report of four cases. Int J Gynecol Cancer. 2007, 17:274-9. 10.1111/j.1525-1438.2006.00747.x

11. Cheson BD, Fisher RI, Barrington SF, et al.: Recommendations for initial evaluation, staging, and response assessment of Hodgkin and non-Hodgkin lymphoma: the Lugano classification. J Clin Oncol. 2014, 32:305968.

12. Kendrick JE IV, Straughn JM Jr: Two cases of non-Hodgkin's lymphoma presenting as primary gynecologic malignancies. Gynecol Oncol. 2005, 98:490-2. 10.1016/j.ygyno.2005.04.033

13. Tilly H, Gomes da Silva M, Vitolo U, et al.: Diffuse large B-cell lymphoma (DLBCL): ESMO Clinical Practice Guidelines for diagnosis, treatment and follow-up. Ann Oncol. 2015, 26:v116-25. 10.1093/annonc/mdv304

14. Vang R, Medeiros LJ, Silva EG, Gershenson DM, Deavers M: Non-Hodgkin's lymphoma involving the vagina: a clinicopathologic analysis of 14 patients. Am J Surg Pathol. 2000, 24:719-25. 